\title{
LUIS MANUEL DEL \\ RIVERO, EL DIARIO \\ EL ESPAÑOL Y LA \\ GUERRA DE 1847
}

Raúl Figueroa Esquer*

El objeto de este pequeño prólogo es rescatar del olvido a un autor español, quien no sólo escribió un libro sobre México, sino que durante el transcurso de la guerra de 1847 dio a la luz una serie de doce artículos titulados La Guerra de México publicados en el diario El Español de Madrid.

\section{El autor}

Luis Manuel del Rivero, abogado asturiano, residió en México a finales de la década de 1830 y escribió, de regreso en Madrid, un libro sobre nuestro país titulado México en $1842 .{ }^{1}$ Agudo análisis de la élite política mexicana y de los diversos ensayos de organización política intentados en México hasta 1841.

En el terreno profesional, durante su estancia en México, trató de abrir un despacho de abogados que defendiera ante los tribunales mexicanos los intereses de ciertos miembros de la colonia española radicada en la antigua Nueva España. Aunque contó con el apoyo del

* Departamento Académico de Estudios Generales, ITAM.

1844 , Madrid, Imprenta y fundición de D.E. Aguado. 
RAÚL FIGUEROA ESQUER

ministro español Ángel Calderón de la Barca, no tengo noticias de que dicho despacho haya abierto sus puertas. ${ }^{2}$

El conocimiento que Del Rivero adquirió sobre México le hizo surgir una simpatía por esta tierra que ya nunca abandonó. Es significativo que inicie la obra citada evocando "el nombre mágico de México" y que los artículos de los que me ocuparé comiencen con la frase siguiente: "Los norteamericanos ocupan ya la hermosa México, orgullo del imperio español, la vez primera después de trescientos años de pacífica existencia profanada por la planta de bárbaro invasor."3

\section{El periódico y su director}

El Español fue un diario madrileño fundado por el publicista malagueño Andrés Borrego (1802-1891). Borrego fue el mejor periodista político del siglo XIX español; quien como liberal peninsular, sufrió persecuciones después de la restauración de la monarquía absolutista de Fernando VII en 1823.

Durante la llamada "Década Ominosa" (1823-1833), Borrego emi-

116 gró a Londres por espacio de tres años aproximadamente. En 1826 lo encontramos en Brasil en compañía de otros ilustres exiliados: Álvaro Flores Estrada, Francisco Díaz Morales y Juan Rumí: "el objetivo de tan extraño viaje era tratar con el emperador Pedro. II la cuestión de la unidad hispano-portuguesa que, en aquellos años de lucha contra el absolutismo monárquico, empezó a atraer especialmente a los liberales de ambas naciones". ${ }^{4}$ En el verano de 1828 don Andrés se encuentra

${ }^{2}$ Desp. 33, de Ángel Calderón de la Barca al ministro de Estado, México, 28 de diciembre de 1841, apud, Relaciones Diplomáticas HispanoMexicanas, 1948, México, El Colegio de México, I, p. 309-10.

${ }^{3}$ Vid. Artículo I, p. 129. Todos los artículos de Luis Manuel Del Rivero aquí citados corresponden a la presente edición.

${ }^{4}$ Andrés Borrego, Historia de una idea, 1869, Madrid. Juan del Nido y Segalerva, La Unión Ibérica. Estudio critico, histórico de este problema formado con cuanto acerca de él [sic] han escrito los historiadores, así 
en París, donde pronto se relacionó con los directores de periódicos liberales franceses. Empezó a colaborar en Le Constitutionnel. A principios de 1830 forma parte de Le Temps. Ahí lo sorprenden las jornadas de julio de 1830 que acabaron con la monarquía reaccionaria de Carlos X, quien pretendió imponer un sistema absolutista obsoleto en su país, como lo hiciera Fernando VII en España.

E1 28 de julio el general Lafayette lo nombró Inspector General de Monumentos Públicos, cargo con el que fue ratificado por la triunfante monarquía de Luis Felipe de Orleáns; dicho nombramiento conllevaba un sueldo anual de 20,000 francos y el título de ciudadano francés. Don Andrés, agradecido, rechazó ambos ofrecimientos. Leamos sus propias palabras: "Yo he tomado parte en esta contienda en la persuasión de que el triunfo de los liberales franceses contribuiría al restablecimiento de la libertad de España. A regresar al seno de España libre se limita mi ambición. No sé lo que en ella me tendrá deparado la suerte, pero el deber me dicta no cambiar de nacionalidad, por gloriosa que sea la francesa, y convertir en un golpe de fortuna lo que ha sido el cumplimiento de un deber de emigrado liberal."5

En efecto, Borrego continúa en su empleo en Le Temps. Alentado por la actitud del gobierno de Luis Felipe y de la llegada a París de exiliados españoles procedentes de Londres, Borrego se decide a la publicación de un periódico: El Precursor, el cual saldría dos veces por semana a partir de septiembre de 1830. El objetivo de dicha publicación era obvio: luchar contra la tiranía de Fernando VII. Como boletín producto de un exilio político tuvo corta vida. Para nosotros es interesante que el 31 de octubre publicara las Bases del Programa Liberal defendido por el periódico, el cual entre otros puntos caros a los liberales proscritos sostiene la necesidad del "reconocimiento de

portugueses como españoles, y los defensores de ella, 1914, Madrid, Tip. de P.P. de Velasco. Apud, Concepción de Castro, Romanticismo, periodismo y política. Andrés Borrego, 1975, Madrid, Tecnos, p. 32.

${ }^{5}$ Andrés Borrego, Episodios de Historia Contemporánea, Madrid, p. 115, apud, Castro, op. cit., p. 34. 


\section{RAÚL FIGUEROA ESQUER}

la independencia de las repúblicas fundadas por nuestros hermanos de América". ${ }^{6}$ Clara alusión a las relaciones que sostuvieron los liberales españoles con diplomáticos y ciudadanos latinoamericanos en Londres.

Fernando VII fallece en 1833. Al año siguiente Borrego regresa a España, y en 1835 funda El Español. Diario de las Doctrinas y de los Intereses Sociales. Sus objetivos son "liberalizar" a la derecha española moderada. Don Andrés, hombre del justo medio, explica sus objetivos con las siguientes palabras: "acometí el intento de liberalizar a los moderados, pareciéndome más asequible que el de infundir mesura en los progresistas, y rectificar los palpables errores de su escuela".?

Su misión con respecto a la facción moderada de los liberales españoles será pues, civilizarla y tornarla culta, tolerante, rica y europeizada. Es por ello que se le considera un liberal-conservador. Que se mantiene, como afirma Concepción de Castro, "equidistante entre el dogmatismo individualista y los extremos irracionales, tras del movimiento romántico; que profesa un individualismo más próximo a Locke que a Bentham y que participa, al mismo tiempo del espíritu romántico que influye en todos los campos políticos hasta la revolución europea de $1848 " .8$ Los diversos diarios de los cuales Borrego fue director son periódicos de "principios" no de partido. Don Andrés "nunca ligará la suerte de sus sucesivos periódicos a la de un partido político". 9 En efecto, Borrego demostrará su independencia política a través de los diversos diarios en los que fungió como director.

Debemos también a la profesora de Castro el esfuerzo de identificar las tres líneas de pensamiento que se van a mantener constantes en

${ }^{6}$ El Precursor, 31 de octubre de 1830, apud, Castro, op. cit., p. 39.

${ }^{7}$ Andrés Borrego, Estudios políticos de la organización de los partidos en España considerada como medio de adelantar la educación constitucional de la nación y de realizar las condiciones del gobierno representativo, 1855, Madrid, Imp. de D. A. Santa Coloma, editor, p. 225, apud, Castro, op. cit., p. 44.

${ }^{8}$ Castro, op. cit., p. 49.

${ }^{9}$ Ibid., p. 44-5. 
Borrego hasta el fin de sus días: liberalismo-conservador inglés, liberalismo católico francés y corriente de crítica social al sistema capitalista. $^{10}$

El Español, tuvo dos épocas: la primera de 1835 a 1837 ; la segunda de 1845 a 1848. La más autorizada biógrafa de Borrego, Concepción de Castro considera la primera etapa de El Español más rica y crítica que la segunda. Esta afirmación está sólidamente sustentada ya que los años de 1835 a 1837 están inscritos en la época de la instauración del régimen liberal en España en lucha contra los carlistas; es el momento de transición política entre el Estatuto Real (virtual Carta Otorgada) sancionado por la reina gobernadora María Cristina y la Constitución de 1837, "obra de los progresistas templados". ${ }^{11}$ En este último año también tendrá lugar la gran desamortización de bienes de la Iglesia llevada a cabo por Juan Álvarez de Mendizábal. Todas estas circunstancias explican porqué la primera etapa de El Español sea superior en amplitud de pensamiento y rigor crítico que la segunda. Durante 1845 a 1848, en plena década moderada (1844-1854), El Español es un periódico "más conservador que en su primera época durante la guerra civil, pues ha desaparecido, lógicamente, el ímpetu revolucionario de aquellos años de lucha frente al absolutismo". ${ }^{12}$ Sin embargo, Borrego logra que su periódico no sea un simple diario ministerial; al contrario, se muestra alejado de "una derecha triunfante, incapaz de comprender el sentido de un posible conservatismo progresivo y tolerante". 13 Pese a todos los problemas económicos que tuvo que hacer frente en estos años Borrego logró sin lugar a dudas que El Español fuera uno de los más prestigiosos diarios madrileños.

En esta segunda etapa se publicaron los artículos de Luis Manuel del Rivero titulados La Guerra de México. Cabe hacer una precisión,

${ }^{10}$ Ibid., p. 50.

"Francisco Cánovas Sánchez, "Los partidos políticos", La era isabelina y el sexenio democrático, 1834-1874, 1981, Madrid, Espasa-Calpe, p. 381-3.

${ }^{12}$ Castro, op. cit., p. 222.

${ }^{13}$ Ibid. 
RAÚL FIGUEROA ESQUER

El Español como diario independiente no era órgano de partido, pero como el resto de los periódicos españoles funcionaba como vehículo de expresión de tendencias o fracciones, grupos de opinión con frecuencia muy fluidos. ${ }^{14}$

\section{Los artículos}

Los doce artículos que aquí nos ocupan aparecieron publicados en $E l$ Español durante exactamente un mes, entre el 9 de noviembre y el 9 de diciembre de 1847. Esto es, cuando en Madrid ya se conocía la ocupación de la ciudad de México por los norteamericanos. En lo referente a la política interna española, cabe destacar que el general Ramón María Narváez había llegado por tercera vez al poder el 5 de octubre del mismo año: "el general Narváez penetraba sable en mano en pleno Consejo de ministros, y los mandaba a todos a sus casas. Fue, caso único en la historia, un golpe de Estado dado por un hombre solo". 15

La Guerra de México no es una historia de la invasión norteameri-

120 cana a nuestro país en sentido estricto, tampoco es una crónica, pues el autor, quien como ya expusimos, había vivido en México - aproximadamente hasta 1840 - no presenció la campaña norteamericana. Lo que Del Rivero se propuso fue explicar cómo había sido posible haber llegado a esa catástrofe.

¿Por qué Del Rivero escribió La Guerra de México? El propio autor nos da la respuesta: "A propósito de la fácil ocupación de México por las tropas norteamericanas, y con el fin de poner al público español en disposición de comprender tan extraño desenlace, emprendimos bosquejar un cuadro sucinto de las situación en que dejó España a aquel

${ }^{14}$ Vicente Palacio Atard, La España del siglo XIX, 1978, Madrid, EspasaCalpe, p. 244.

15 José Luis Comellas, Los moderados en el poder, 1844-1854, 1970, Consejo Superior de Investigaciones Cientificas, p. 251. 
país, vicisitudes por las que ha pasado después, y relaciones que ha sustentado con [su] vecino, los Estados Unidos, hasta el término de verse invadido por éste y sojuzgado." 16

Del Rivero pretendió en los primeros artículos resaltar la obra de España en México, especialmente durante el siglo XVIII hasta culminar con la emancipación de nuestro país. Por otra parte, en el resto de los artículos utilizará el método de contrastar la triste situación de México con el engrandecimiento norteamericano y su sólida estructura económica y política.

Del Rivero resalta las características que consideraba como pruebas de fortaleza del virreinato de la Nueva España; toda esta grandeza y prosperidad insertos, claro está, en el marco de las reformas borbónicas. Muchas de sus apreciaciones recuerdan a Lucas Alamán, si bien es cierto que Del Rivero escribió antes que el prócer conservador.

Trata de presentar un cuadro idílico del siglo XVIII cuando afirma que: "La Iglesia en perfecta armonía con el Estado, satisfacía copiosamente a la necesidades espirituales, y formaba el lazo íntimo y que unía a todas las clases." 17 Afirmación completamente insostenible, pues lo que el Estado borbónico había hecho desde 1732 era restarle fuerza económica y política a la Iglesia novohispana en todos los sentidos. Baste recordar la expulsión de la Compañía de Jesús en 1767 y la aplicación de la Real Cédula de Consolidación de Vales Reales, de 1804 a 1809.

Resulta curioso que el autor, quien había escrito un libro bastante documentado sobre México en 1841, y, que por lo tanto, conocía al dedillo la primera república centralista (1836-1841) haya sido tan parco en sus artículos al referirse a esa época.

Para interesar al lector español inicia sus artículos con un tono patético, incitando a sus connacionales a llorar la caída de México: "lloremos la suerte de la ciudad infortunada, cuyos numerosos hijos no han sido [capaces de] defenderla de un puñado de bisoños aventure-

${ }^{16}$ Vid. Artículo XII y último, p. 201.

${ }^{17}$ Vid. Artículo I, p. 131. 
RAÚL FIGUEROA ESQUER

ros; lloremos mil víctimas inocentes sacrificadas al furor de la guerra por la ambición de unos y por la impericia o abatimiento de otros; [...] lloremos la súbita decadencia de una nacionalidad que prometía tantos días de vigor y de pujanza". 18

Afirma que la situación de los indios, "la clase realmente desvalida [...] mejoraba continuamente en nuestras manos". ${ }^{19}$ Después de resaltar todo lo positivo, reconoce que el gobierno novohispano no era perfecto, sobre todo porque España no proporcionó experiencia y educación previa en las tareas de gobierno a los mexicanos. Sin embargo, sostiene que la independencia forzó el curso natural de las cosas.

Liga los inicios del proceso de emancipación mexicano con la revolución francesa y con la invasión de España por Napoleón. Toma partido claramente por los realistas fieles a Fernando VII. Por lo tanto el retrato que presenta de Miguel Hidalgo es sumamente parcial: "El cura Hidalgo, no conocido por ningún antecedente honroso, fue quien lanzó el primer grito de la rebelión, cuya causa, engrosándose súbitamente con turbas inmensas de indios y gente perdida, apenas regimentada por algunos militares, vino toda cubierta de sangre inocente, de robos y de incendios a estrellarse en el Monte de las Cruces casi a la vista de México, en Aculco, en Guanajuato y en el puente de Calderón, dispersadas aquí las turbas y el mismo caudillo en fuga y luego preso y ajusticiado pulularon los facciosos en el país [...]."20

Ante la indisciplina de las "turbas" contrapone la actitud de los realistas: "Por el lado del gobierno se encontraba la gran masa de intereses y de personas sensatas o ilustradas del país, que si bien en el fondo de su corazón anhelaban la emancipación, no la querían por medio de los horrores de una tan bárbara guerra civil, ni en unas manos, en lo general tan soeces y manchadas de sangre inocente como las que por ella luchaban." 21

${ }^{18}$ Vid. Artículo I, p. 130.

${ }^{19}$ Vid. Ibid., p. 133.

${ }^{20} \mathrm{Vid}$. Artículo III, p. 142.

${ }^{21}$ Vid. Ibid., p. 143. 
En los artículos tercero y cuarto trata de todo el movimiento insurgente-popular hasta 1820 y de la elevación y caída de Iturbide; mientras que en el quinto, expone el caos y la anarquía de México de 1824 a 1847, calificada como política interna difusa.

El autor constantemente escribe sobre la "revolución mexicana" como un continuum desde el inicio del proceso emancipador mexicano hasta el año en que escribe. Tal vez para Del Rivero el concepto "revolución mexicana" era equivalente al caos y a la anarquía, que en efecto caracterizaron al México independiente de 1821 a 1855.

Si bien considera que bajo el dominio norteamericano habrá para México orden y progreso material, lo matiza al afirmar: "pero no hay bienes ningunos capaces de resarcir el honor perdido, de colmar el vacío dejado por la pérdida de la independencia; creemos que el honor y la independencia es lo último que respeta la desgracia, lo último que tiene que perder un pueblo lo mismo que un individuo, y cuando se ha llegado a este abismo de desventura, es necesario despedirse de la vida". 22

Del Rivero arremete contra aquellos a los que les es indiferente la suerte de México: "Dicen otros, ¿qué importa a la humanidad el que subsista o desaparezca la nacionalidad mexicana? Lo que realmente le importa es, que el privilegiado suelo que ella ocupa sea restituido a la cultura de la civilización. Pero yo que me precio de humanitario, no tanto sin embargo, que no deje en mi corazón un puesto privilegiado para el más decidido patriotismo; y este sentimiento, tan puro cuando menos como el primero, se lastima horriblemente de que se disipe como el humo el patrimonio de honor y riqueza acumulados en las manos recias de un heredero presuntuoso por la sobriedad, por la virtud, por el trabajo infatigable y oscuro de muchas generaciones de honrados y animosos españoles. La humanidad, por otra parte, no gana con la supresión de grandes y legítimas nacionalidades, ella prefiere antes bien verse completamente representada en la tierra, y para esto ha derramado con variedad sus tesoros, invistiendo con una parte

${ }^{22}$ Vid. Artículo vi, p. 161. 


\section{RAÚL FIGUEROA ESQUER}

de ellos a cada raza, a cada pueblo. Enhorabuena que estas grandes unidades se salgan al encuentro en el camino de la vida para auxiliarse mutuamente con afecto fraternal, mas nunca para combatirse y para absorberse. Creo, pues, que al interesarme por la noble nacionalidad española en el Nuevo Mundo, me intereso realmente por la causa de la humanidad, y muy especialmente por la de la América, en cuyo suelo está ya sobradamente representada la raza sajona con todos sus instintos, con todas sus perfecciones y defectos." 23

En los artículos VI y VII el autor ofrece una breve historia de las colonias inglesas en América del Norte y de las causas de su emancipación de su metrópoli. Compara la dependencia que la Nueva España tenía con la Península y concluye que lo que fue motivo de felicidad para los Estados Unidos ha causado la desgracia de México. Por otra parte, también compara el crecimiento de los Estados Unidos con el de Rusia, "el otro pueblo del norte". Del Rivero no puede evitar profetizar al afirmar que los norteamericano llegarán a Panamá, mientras los rusos se expandirán hasta Constantinopla.

También expone los factores geográficos en el desarrollo de las colonias inglesas, la forma de organización política de los Estados

124 Unidos, la constitución federal, la cual le parece adecuada para ese país. No obstante los elogios realiza una severa crítica sobre la existencia de la esclavitud. ${ }^{24}$

No oculta el carácter depredador que ha tenido la expansión norteamericana al avasallar a tribus indígenas, tan valientes como los semínolas de Florida, y el papel que ha desempeñado en ello su ejército.

Con mucha precisión narra la historia de la expansión norteamericana por el Sur; los tratados europeos que produjeron la retrocesión de la Luisiana a Francia producto de la miopía de Godoy y Carlos IV; así como el deseo de los norteamericanos de incluir a Texas dentro de la Luisiana, que compraron a Napoleón en $1803 .^{25}$

\footnotetext{
${ }^{23} \mathrm{Ibid}$.

${ }^{24}$ Vid. Artículos VI y VII, p. 162-71.

${ }^{25}$ Vid. Artículo VIII, p. 173.
} 
Es posible rastrear la concepción económica que tiene Rivero, ya que es un enemigo decidido del proteccionismo aduanero. La industria norteamericana, afirma, se ha ido desarrollando a partir del bloqueo continental decretado por Napoleón y las múltiples restricciones que entonces sufría el tráfico comercial, "fueron causa principal de que naciese la industria americana, y de que posteriormente se haya ido desenvolviendo a pesar de la mentida protección del llamado sistema protector, que también por allá domina, y da de sí bien amargos frutos". 26

Rivero da por descontada la desaparición de México, con esto en mente, llama la atención del público español recordándole la importancia geoestratégica que tiene Cuba - entonces posesión españolaisla que cierra el "seno mexicano", que con el golpe propiciado sobre México se convertirá en un lago norteamericano. Sostiene, y con razón, que no faltarán presiones de todo tipo por parte de los norteamericanos para comprar la "perla de las Antillas". La adquisición de la isla por los Estados Unidos será una demanda para "su comodidad y defensa". 27

Atisba la grave situación por la que está pasando el ejército norteamericano en México al afirmar que "no basta conquistar la capital, es necesario dominar el país". ${ }^{28}$

A continuación considera que la disolución de México es producto de las "felices intrigas de los diplomáticos norteamericanos". Uno de sus propósitos fue "consumir todo entero el elemento español, único capaz de dar consistencia separada a aquella sociedad y de resistir la asimilación intentada desde un principio por la sociedad anglosajona del Norte", 29

Con cierto cuidado relata la historia de Texas desde que formaba parte de la Nueva España, hasta que obtuvo su independencia de México en 1836.

${ }^{26}$ Vid. Artículo IX, p. 184.

${ }^{27}$ Vid. Ibid., p. 186.

${ }^{28}$ Ibid.

${ }^{29}$ Vid. Artículo IX, p. 187. 


\section{RAÚL FIGUEROA ESQUER}

En su último artículo realiza una serie de reflexiones después de la caída de la ciudad de México. Considera que para la política exterior de España, y muy especialmente para los españoles residentes en México, "el medio más seguro de volvernos a hacer odiosos, sería el de presentarnos allí con la pretensión de regeneradores monárquicos, y unida la Europa en este común pensamiento, aún quedaría un trabajo infinito para hacerse aceptar a los mismos que por él habían de ser beneficiados". ${ }^{30}$ La anterior afirmación atestigua que Del Rivero conocía muy bien el carácter mexicano y el sentido de respeto que al abogado asturiano le producía la "otredad". Pudo columbrar que el antiguo virreinato ya era una nación diferente. Pocos españoles de su tiempo tuvieron una mente lúcida como Del Rivero.

Nuestro autor afirma que el principio monárquico producía el más completo desprecio por parte de los norteamericanos. Asimismo, sostiene que la monarquía no podía ser apoyada por el pueblo mexicano, con excepción del clero y una que otra clase. "Aborrecióse allí a los ingleses y singularmente a los franceses, y en general a todo extranjero, en cuyo odio nos cabe a nosotros una parte, si bien la más pequeña, porque han llegado a persuadirse que entre todos, los que llevan miras

126 más desinteresadas y más en armonía con el bien general del país son los españoles como particulares y como gobierno." 31

Del Rivero señala con clarividencia que el único camino para México es transigir con el invasor, "decidirse a hacer los más grandes sacrificios no sólo de territorio, sino hasta de nacionalidad para poder vivir en paz con tan terrible vecino, aguardando mejores días". ${ }^{32}$

En sus últimas reflexiones, Del Rivero se nos presenta como un liberal que está en contra del poder político de la Iglesia católica en México, corporación que "ha prohibido la inmigración", y también en contra del ejército "que tantos daños ha causado y nada bueno ha hecho". 33

${ }^{30} \mathrm{Vid}$. Artículo XII y último, p. 207.

${ }^{31}$ Ibid.

${ }^{32}$ Vid. Ibid., p. 208.

${ }^{33}$ Ibid. 
Cree que México pasará por un período de protectorado y tutela por parte de los Estados Unidos. Finalmente concluye: "así no se habrá salvado todo, pero se habrá salvado lo posible, y el país se regenerará”.

\section{Conclusiones}

Luis Manuel del Rivero representa una línea editorial en completa consonancia con el diario que acogió sus doce largos artículos de fondo sobre La Guerra de México. Esto es, que El Español dirigido por Andrés Borrego representa en el espectro ideológico español la línea liberal-conservadora, que si bien carecía de un equipo de políticos dispuestos a poner en marcha la "liberalización" de la derecha española, muestra que un sector ilustrado de la opinión pública peninsular se opuso a los planes de implantación de una monarquía borbónica en México, prohijados por los gobiernos de los liberales moderados dirigidos por el general Ramón María Narváez, durante 1845 y 1846, planes que estuvieron a punto de llevarse a cabo en nuestro país, como lo ha demostrado Miguel Soto. ${ }^{34}$ La lectura de La Guerra de México demuestra que dentro de las corrientes de opinión en España hubo periódicos destacados, entre ellos El Español, que adoptaron una postura completamente hostil a la línea editorial del periódico ministerial de Narváez: El Heraldo.

El autor, preso de cierto lirismo muy de la época, concluye sus artículos realizando una invocación dirigida a la clase política mexicana: "efectivamente después de una derrota tal y de un tan profundo abatimiento, los hombres pensadores de aquel país deben de haber adquirido la convicción de que la antigua nacionalidad no puede ya por sí levantar a la sociedad postrada con ella en tierra, y es preciso que esa sociedad se regenere bajo los auspicios de un nuevo principio: el principio democrático". "Ciento cincuenta años después de escrito

${ }^{34}$ Cfr. Miguel Soto, La conspiración monárquica en México, 1988, México, Eosa.

${ }^{35}$ Vid. Artículo XII y último, p. 208. 


\section{RAÚL FIGUEROA ESQUER}

lo anterior por Luis Manuel del Rivero desde ese gran periódico madrileño, los mexicanos seguimos esperando el día en que pueda triunfar plenamente entre nosotros el principio que el ilustre abogado asturiano preconizara como el mejor antídoto para rebustecer la sociedad mexicana, para que no fuese presa de invasiones extranjeras. 